\title{
Albumin nanoparticles for glutathione-responsive release of cisplatin: New opportunities for medulloblastoma
}

\author{
Giuseppina Catanzaro $^{\mathrm{a}, \mathrm{b}, 1}$, Manuela Curcio ${ }^{\mathrm{c}, *, 1}$, Giuseppe Cirilloc \\ Umile Gianfranco Spizzirri $^{\mathrm{c}}$, Zein Mersini Besharat ${ }^{\mathrm{d}}$, Luana Abballe ${ }^{\mathrm{a}}$, Alessandra Vacca ${ }^{\mathrm{a}}$, \\ Francesca Iemma ${ }^{c}$, Nevio Picci ${ }^{c}$, Elisabetta Ferretti ${ }^{\mathrm{a}, \mathrm{e}}$
}

a Department of Experimental Medicine, Sapienza University, Rome 00161, Italy

${ }^{b}$ Pasteur Institute Italy, Fondazione Cenci Bolognetti, Rome 00161, Italy

${ }^{\mathrm{c}}$ Department of Pharmacy Health and Nutritional Science, University of Calabria, Rende 87036, Italy

d Department of Molecular Medicine, Sapienza University, Rome 00161, Italy

e Neuromed Institute, Pozzilli 86077, Italy

\section{A R T I C L E I N F O}

\section{Article history:}

Received 24 October 2016

Received in revised form 6 December 2016

Accepted 8 December 2016

Available online 9 December 2016

\section{Keywords:}

Albumin nanoparticles

Redox responsivity

Glutathione

Biocompatibility

Medulloblastoma

Cisplatin

\begin{abstract}
A B S T R A C T
Redox-responsive nanoparticles were synthesized by desolvation of bovine serum albumin followed by disulfide-bond crosslinking with $N, N^{\prime}$-Bis (acryloyl) cystamine. Dynamic light scattering and transmission electron microscopy studies revealed spherical nanoparticles (mean diameter: $83 \mathrm{~nm}$, polydispersity index: 0.3) that were glutathione-responsive. Confocal microscopy revealed rapid, efficient internalization of the nanoparticles by Daoy medulloblastoma cells and healthy controls (HaCaT keratinocytes). Cisplatin-loaded nanoparticles with drug:carrier ratios of $5 \%, 10 \%$, and $20 \%$ were tested in both cell lines. The formulation with the highest drug:carrier ratio reduced Daoy and HaCaT cell viability with $\mathrm{IC}_{50}$ values of 6.19 and $11.17 \mu \mathrm{g} \mathrm{mL}^{-1}$, respectively. The differential cytotoxicity reflects the cancer cells' higher glutathione content, which triggers more extensive disruption of the disulfide bondmediated intra-particle cross-links, decreasing particle stability and increasing their cisplatin release. These findings support continuing efforts to improve the safety and efficacy of antineoplastic drug therapy for pediatric brain tumors using selective nanoparticle-based drug delivery systems.
\end{abstract}

(C) 2016 Elsevier B.V. All rights reserved.

\section{Introduction}

Medulloblastomas (MBs) are among the primary brain tumors most frequently diagnosed in pediatric patients. They occur mainly in infants and children but occasionally also adolescents (or even adults). MBs arise in the posterior fossa and fourth ventricle and have a high propensity to metastasize (Coluccia et al., 2016; Morfouace et al., 2014). Most MBs are still treated with the combined use of aggressive surgical resection followed by multiagent chemotherapy and, for children over 3 years of age, craniospinal irradiation. Although this approach has considerably improved the 5-year survival rates of patients with MBs, the treatments themselves frequently cause acute and/or long-term

\footnotetext{
* Corresponding author at: Department of Pharmacy Health and Nutritional Science, University of Calabria, Edificio Polifunzionale, 87036 Rende, Italy. E-mail address: manuela.curcio@unical.it (M. Curcio).

1 These authors contributed equally to this work.
}

adverse effects, many of which severely diminish the survivors' quality of life (Matheson et al., 2016; Nageswara Rao et al., 2014).

For the past 20 years (Parhizkar et al., 2016), the alkylating agent cisplatin (CPT) has been a mainstay of MB chemotherapy. However, its high toxicity often results in major adverse effects, including stunted growth, irreversible hearing loss, and renal dysfunction. These features severely limit the CPT doses that can be used and consequently the therapeutic benefits that can be achieved in children with MB (Dhar et al., 2008; Nageswara Rao et al., 2014; Wehe et al., 2014).

Increasingly dynamic collaboration between oncologists, biologists, and material scientists has generated a number of proposals for improving the safety and efficacy of brain tumor chemotherapy regimens (Gharpure et al., 2015; Kim et al., 2010; Pacardo et al., 2015; Stylianopoulos and Jain, 2015; Wang et al., 2012). One of the most versatile options involves the use of nanoscale polymeric carriers (Eetezadi et al., 2015; Fernandes et al., 2015; Johnstone et al., 2016): they offer a high surface area for drug binding and controllable physical-chemical and biologic properties, which can 
be exploited to regulate delivery rates of the drug, thereby improving its pharmacokinetics, therapeutic index, and safety profile (Kumari et al., 2016). Several nanoparticles have also been shown to cross the BBB and accumulate in the CNS (Calvo et al., 2001; Ulbrich et al., 2009), essential requisites for carriers destined for use in the treatment of brain tumors.

Human and bovine albumin have both been widely used to create nanoparticle systems for delivering drugs to a variety of organs. The advantages of albumin include a high drug-binding capacity (Elzoghby et al., 2012), biodegradable and biocompatible properties, and the fact that it already has U.S. Food and Drug Administration approval for pharmaceutical applications (Raval et al., 2015). The hyperpermeability of intratumoral blood vessels enhances the delivery of albumin nanoparticles (A-NP) to neoplastic tissues, where they are readily taken up by cancer cells to meet their increased need for amino acids and energy (Neumann et al., 2010). A-NP accumulation in these cells is also promoted by the reduced venous clearance of most solid tumors (Noguchi et al., 1998). Importantly, several unmodified A-NPs have been shown to cross the BBB via adsorptive transcytosis triggered by electrostatic interactions between the polycationic proteins and the negatively charged brain membrane (Hervé et al., 2008), and their use is not associated with any impairment of locomotor, explorative, or cognitive functions (Bergonzi et al., 2016).

Carriers capable of responding to specific conditions within a cell, such as changes in the redox state, $\mathrm{pH}$, or enzyme activity profile, can enhance a drug's efficacy and specificity while significantly reducing its side effects (Qiu and Park, 2012). Solid tumors, for example, frequently present elevated levels of the master antioxidant, glutathione (GSH) (Ilangovan et al., 2002), which can be exploited to trigger targeted release of anticancer drugs. GSH-responsive delivery can be achieved by using $N, N^{\prime}$-bis (acryloyl)cystamine (BAC) as a disulfide-bond-containing crosslinker in the formation of NPs from naturally occurring polymers (e.g. chitosan and chitosan derivatives). In the presence of high GSH levels, the disulfide bridges within the polymer network undergo reduction, a reaction which destabilizes the NP and increases the release of the drug they are carrying (Curcio et al., 2015b).

In literature, several examples of redox-responsive materials based on serum albumin are presented. Wang et al. prepared a selfcross-link strategy to fabricate HSA nanoparticles stabilized by intermolecular disulfide bonds and dissolvable in reducing media (Wang et al., 2013a). In a work of 2015 (Shi et al., 2015), pH- and redox-sensitive nanoparticles were prepared by covalent linkage of a $\mathrm{Pt}^{\mathrm{IV}}$ prodrug to human serum albumin (HSA) to form a disulfide containing Pt-HSA complex, followed by conjugation to calcium phosphate (CaP) nanoparticles. Upon cellular uptake, $\mathrm{CaP}$ is decomposed with $\mathrm{pH}<6.0$, releasing $\mathrm{Pt}-\mathrm{HAS}$, while the $\mathrm{Pt}^{\mathrm{IV}}$ prodrug is dissociated from HSA in the form of cisplatin after disulfide reduction by GSH. Adriamycin was also linked to HSA using a disulfide-containing spacer to obtain an amphiphilic specimen able to form micellar-like nanoparticles in which the drug release was controlled by GSH concentration (Chen et al., 2015).

Finally, Molina et al. employed a nanoprecipitation method to obtain HSA nanoparticles decorated with the photosensitizer chlorin e6. The nanoparticles were stabilized using disulfidecontaining cross-linker to create a smart drug delivery system that is activated only upon nanoparticles degradation in the reducing intracellular environment (Molina et al., 2016).

In this study, we developed and tested redox-responsive bovine serum albumin (BSA)-nanoparticles (RNPs) for use in the delivery of CPT to MB cells. The RNPs were synthesized by means of a desolvation technique in which BAC was used as GSH-responsive cross-linker. We used transmission electron microscopy (TEM) for morphological characterization of the RNPs and dynamic light scattering (DLS) to assess their size distribution and redox responsivity. To assess the applicability of these RNPs for the treatment of $\mathrm{MB}$, we measured their in vitro cytotoxicity in healthy human keratinocyte (HaCaT) and human MB (Daoy) cell lines. Finally, confocal microscopy was used to confirm the effective uptake of the RNPs by both cell lines.

\section{Materials and methods}

\subsection{Materials}

The following reagents were purchased from Sigma Aldrich (St Louis, MO): bovine serum albumin (BSA), cystamine dihydrochloride, acryloyl chloride, fluorescein-5-isothiocyanate (FITC), cisplatin (CPT), glutathione (GSH), $\mathrm{NaOH}, \mathrm{NaCl}$, reagent-grade ethanol, reagent-grade dimethyl sulfoxide (DMSO), paraformaldehyde (PFA), Triton X-100, Dulbecco's Modified Eagle Medium (DMEM), phosphate-buffered saline (PBS), sodium carbonate buffer, $200 \mathrm{mM}$ glutamine (Gln), $100 \mathrm{mM}$ sodium pyruvate, $100 \times$ non-essential amino acids (NEAA), and antibiotic solution ( 100 units $\mathrm{mL}^{-1}$ penicillin and $10000 \mu \mathrm{g} \mathrm{mL}^{-1}$ streptomycin) were from Sigma Aldrich (St Louis, MO). Minimum Essential Media (MEM) and fetal bovine serum (FBS) were from Gibco-Invitrogen (Carlsbad, CA). Phalloidin was from Thermo Scientific (Waltham, MA, USA). The CellTiter $96 \mathrm{AQ}_{\text {ueous }}$ One Solution Cell Proliferation assay was from Promega (Madison, WI, USA).

\subsection{Cell culture}

Human keratinocytes (HaCaT) and human MB (Daoy) cells purchased from ATCC were cultured at $37^{\circ} \mathrm{C}$ in a humidified $5 \% \mathrm{CO}_{2}$ incubator. Briefly, HaCaT cells were grown in DMEM supplemented with $10 \% \mathrm{FBS}, 2 \mathrm{mM}$ Gln, and 100 units $\mathrm{mL}^{-1}$ antibiotic solution. Daoy cells were maintained in MEM supplemented with $10 \% \mathrm{FBS}$, $1 \mathrm{mM}$ sodium pyruvate, $1 \times \mathrm{NEAA}$, and 100 units $\mathrm{mL}^{-1}$ of antibiotic solution.

\subsection{Synthesis of $\mathrm{N} \mathrm{N}^{\prime}$-Bis (acryloyl) cystamine (BAC)}

BAC was prepared as described elsewhere (Sun et al., 2010). Briefly, $50 \mathrm{~mL}$ of an aqueous solution $(1.0 \mathrm{M})$ of cystamine dihydrochloride was placed in a $250 \mathrm{~mL}$ three-neck flask equipped with a thermometer and two 50-mL dropping funnels. Then, $10 \mathrm{~mL}$ acryloyl chloride solution in dichloromethane $(15.0 \mathrm{M})$ and $20 \mathrm{~mL}$ $\mathrm{NaOH}$ aqueous solution $(10.0 \mathrm{M})$ were simultaneously added, dropwise, at $0-5{ }^{\circ} \mathrm{C}$ and allowed to react at room temperature (RT) for $16 \mathrm{~h}$. The BAC thus obtained was purified by recrystallization from ethyl acetate. The reaction yield was $73 \%$ ca.

\subsection{Synthesis of FITC-BSA}

BSA was labeled with FITC, as previously described (Ke et al., 2015). BSA (60 mg) was dissolved in $3.0 \mathrm{~mL}$ sodium carbonate buffer $(100 \mathrm{mM}, \mathrm{pH} 9.2)$, and $0.6 \mathrm{~mL}$ FITC solution in sodium carbonate buffer $\left(1.0 \mathrm{mg} \mathrm{mL}^{-1}\right)$ was then added and allowed to react at RT for $3 \mathrm{~h}$. The FITC-BSA thus obtained was purified by dialysis against $5.0 \mathrm{mM}$ phosphate buffer ( $\mathrm{pH}$ 3.0) for two days.

\subsection{Preparation of RNPS}

RNPs were prepared using a previously described de-solvation method with minor modifications (Wolak and Thorne, 2013). BSA powder ( $200 \mathrm{mg}$ ) was added to $200 \mathrm{~mL}$ distilled water. The $\mathrm{pH}$ was then adjusted to 10 with $0.1 \mathrm{M} \mathrm{NaOH}$ while the mixture was stirred at $500 \mathrm{rpm}$, and the $\mathrm{NaCl}$ concentration was fixed at $10 \mathrm{mM}$. The 
de-solvating agent (ethanol) was added to the BSA solution dropwise at a rate of $1 \mathrm{~mL} \mathrm{~min}^{-1}$ until the solution became just turbid. Finally, $2.0 \mathrm{~mL}$ of the BAC-ethanol solution $\left(10 \mathrm{mg} \mathrm{mL}^{-1}\right)$ was added to induce intra-particle cross-linking. The solution was stirred continuously at $500 \mathrm{rpm}$ and $50^{\circ} \mathrm{C}$ for $48 \mathrm{~h}$. The RNPs thus obtained were purified by two 30 -min cycles of centrifugation at $20,000 \mathrm{~g}$ and re-dispersion in ethanol to remove unreacted chemicals and free BSA molecules.

\subsection{RNPs characterization}

The morphological analysis was carried out by transmission electron microscopy (TEM) using a Hitachi S-3500N microscope (Hitachi Science Systems, Ltd., Ibaraki, Japan). RNP size and size distribution were determined by dynamic light scattering (DLS) analysis using a 90 Plus Particle Size Analyzer (Brookhaven Instruments Corporation, New York, NY, USA) at $25.0 \pm 0.1^{\circ} \mathrm{C}$. The autocorrelation function was measured at $90^{\circ}$ and the laser beam was operating at $658 \mathrm{~nm}$. The polydispersity index (P.I.) was used as a measure of the size distribution. It was directly obtained from the instrumental data fitting procedures using inverse Laplace transformation and CONTIN methods. P.I. values $<3$ indicate homogenous and mono-disperse populations (Curcio et al., 2015c). The same methodology was employed for the determination of the GSH-induced destabilization by incubating RNPs in PBS ( $\mathrm{pH} 7.4$ ) solution in the absence or presence of GSH $(10 \mu \mathrm{M}$ or $10 \mathrm{mM})$, for $24 \mathrm{~h}$ under stirring at RT.

\subsection{Drug loading}

CPT was loaded into RNPs as follows: in separate experiments, 25 and $50 \mathrm{mg}$ of preformed empty NPs were wetted with $2.0 \mathrm{~mL}$ of a concentrated drug solution $\left(2.5 \mathrm{mg} \mathrm{mL}^{-1}\right)$. After 3 days, under slow stirring at $25^{\circ} \mathrm{C}$, the NPs were filtered and dried at reduced pressure in the presence of $\mathrm{P}_{2} \mathrm{O}_{5}$ to a constant weight.

The loading efficiency percentage (LE\%) was determined by HPLC analysis of the filtered solvent according to the following Eq. (1):

$L E(\%)=\frac{C_{i}-C_{0}}{C_{i}}$

Here $C_{\mathrm{i}}$ and $C_{0}$ were the concentrations of drug in the solution before and after the loading study, respectively.

The drug loaded percent (DL\%) was calculated according to the following Eq. (2):

$D L(\%)=\frac{C P T(m g)}{R N P_{S}(m g)} \times 100$

The HPLC equipment consisted of a Jasco PU-2089 Plus liquid chromatograph equipped with a Rheodyne 7725i injector (fitted with a $20 \mu \mathrm{L}$ loop), a Jasco UV-2075 HPLC detector operating at $254 \mathrm{~nm}$, and a Jasco-Borwin integrator. A reversed-phase C18 column ( $\mu$ Bondapak, $10 \mu \mathrm{m}$ of $250 \times 4.6 \mathrm{~mm}$ internal diameter obtained from Waters) was used. The mobile phase consists of a methanol:water:acetonitrile mixture (40:30:30v/v/v), and $1.1 \mathrm{~mL}$ $\mathrm{min}^{-1}$ flow rate was maintained throughout the analysis (Kaushik et al., 2010).

\subsection{MTS assay}

Cytotoxicity was evaluated by using the [3-(4,5-dimethylthiazol-2-yl)-5-(3-carboxymethoxyphenyl)-2-(4-sulfophenyl)-2Htetrazolium, inner salt, MTS] assay. HaCaT cells $(10,000$ cells/well) and Daoy cells ( 4000 cells/well) were seeded in $100 \mu \mathrm{L}$ of culture medium in 96 -well plates and incubated overnight at $37^{\circ} \mathrm{C}$ in $5 \%$
$\mathrm{CO}_{2}$. The medium was then removed, $100 \mu \mathrm{L}$ of free CPT or freshly prepared CPT-loaded RNPs were added, and the cells were incubated for $24 \mathrm{~h}$ under standard conditions. To evaluate cell toxicity, the medium was removed, the cells were washed twice with PBS, and fresh culture medium $(100 \mu \mathrm{L})$ was added. MTS $(20 \mu \mathrm{L})$ was added directly to culture wells, and the plates were incubated for an additional $2 \mathrm{~h}$ at $37^{\circ} \mathrm{C}$ in $5 \% \mathrm{CO}_{2}$. Absorbance at $490 \mathrm{~nm}$ was then measured by a microplate reader (Promega). Cells cultured in fresh culture medium were used as negative controls, while culture medium alone was used for blank correction.

\subsection{Cellular uptake of RNPs}

FITC-labeled RNPs prepared as described above were used to assess cellular uptake. HaCaT cells (40,000 cells/well) and Daoy cells $(10,000$ cells/well) were seeded in $300 \mu \mathrm{L}$ of culture medium in 8-well glass slides (Thermo Scientific, Waltham, MA, USA) and incubated overnight at $37^{\circ} \mathrm{C}$ in $5 \% \mathrm{CO}_{2}$. The cells were then incubated with $32 \mathrm{ug} / \mathrm{mL}$ of FITC-labeled RNPs for $3 \mathrm{~h}$. The cells were then washed twice with PBS and fixed with $4 \%$ PFA for $10 \mathrm{~min}$ at RT. After three washes with PBS, 5 min of incubation with $0.1 \%$ Triton X-100, and three additional PBS washes, cells were stained with phalloidin $(1: 100)$ for $15 \mathrm{~min}$ at RT. Nuclei were counterstained with Hoechst reagent. Slides were mounted and images were acquired using a FV1200 MPE laser scanning confocal microscope (Olympus) with an UPlanSAPO $40 \times / 0.95$ NA objective. Images were processed using Imaris 8.1 software (Bitplane, Zürich, $\mathrm{CH})$.

\subsection{Statistical analysis}

All experiments were performed in triplicate, and data reported are the means \pm S.D. of three independent experiments. Statistical analysis and plotting were performed with GraphPad Prism, Version 6.0 (GraphPad Software Inc., San Diego, California). The $\mathrm{IC}_{50}$ was calculated using a nonlinear regression analysis, the sigmoidal four-parameter logistic curve (4PL). Two-way ANOVA was used to assess the significance of the results, and $p$-values of less than 0.05 were considered significant. Significance of $\mathrm{IC}_{50}$ values in $\mathrm{HaCaT}$ vs Daoy was determined with unpaired two-tailed $t$-test.

\section{Results}

\subsection{Synthesis and characterization of RNPS}

The RNPs were prepared using a two-step procedure that involved the creation of BSA nanoparticles with a desolvation method and subsequent crosslinking with BAC. Because the formation of RNPs was influenced by electrostatic attraction and repulsion between BSA molecules, which varied with the $\mathrm{pH}$ and ionic strength (Jun et al., 2011), desolvation was carried out at $\mathrm{pH}$ 10 and a $\mathrm{NaCl}$ concentration of $10 \mathrm{mM}$. The crosslinking process involves a Michael-type addition reaction between the nucleophilic groups in the protein side chain (free amino, hydroxyl, and thiol groups) and acrylic moieties of BAC (Fig. 1) (Curcio et al., 2015b).

The RNPs were spherical with a narrow size range (mean diameter: $83 \mathrm{~nm}$, P.I. 0.3), as confirmed by combined TEM/DLS studies (Figs. 2 and 3A). To investigate their GSH-responsivity, additional DLS analyses were performed on the RNPs after $24 \mathrm{~h}$ incubation in PBS alone (Fig. 3A) or PBS with two different concentrations of GSH ( $\mathrm{pH} 7.4)$ : the $10 \mu \mathrm{M}$ GSH concentration (Fig. 3B) was used to mimic that of the extracellular matrix, and the $10 \mathrm{mM}$ GSH solution (Fig. 3C) was employed as a model for intracellular environment of cancer cells. The size range of the 


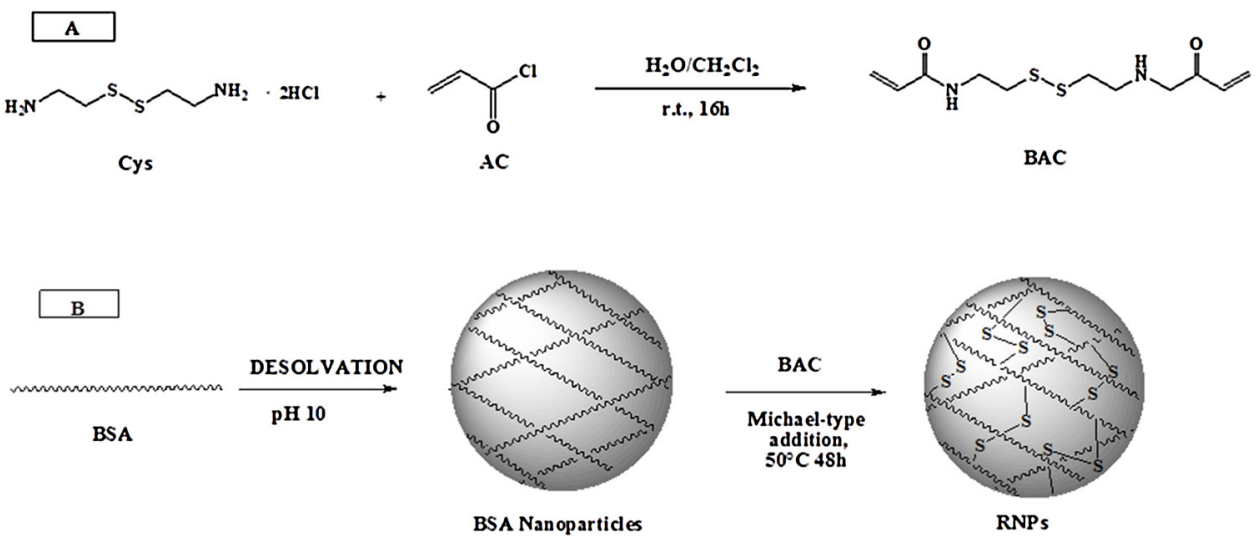

Fig. 1. Schematic representation of RNPS synthesis. A) Synthesis of $N, N^{\prime}$-Bis (acryloyl) cystamine (BAC); B) Synthesis of RNPs by desolvation.

RNPs remained stable over time in the absence of GSH and in the lower-concentration solution (Fig. $3 \mathrm{~A}$ and $3 \mathrm{~B}$, respectively). In contrast, in the presence of GSH $10 \mathrm{mM}$, the mean diameter and P.I. of the RNPs increased significantly (to $167 \mathrm{~nm}$ and 0.47 ), changes that could be attributed to the rupture of crosslinking points in RNPs and consequent swelling of the network.

\subsection{Biocompatibility of RNPS}

The Daoy human MB cell line was used in experiments designed to assess the efficacy of the RNPs as drug-delivery vehicles for treating MB. HaCaT cells, a spontaneously transformed keratinocyte cell line, were employed to test RNP toxicity on healthy cells (Wolff et al., 2013; Laner-Plamberger et al., 2013). Cells of both

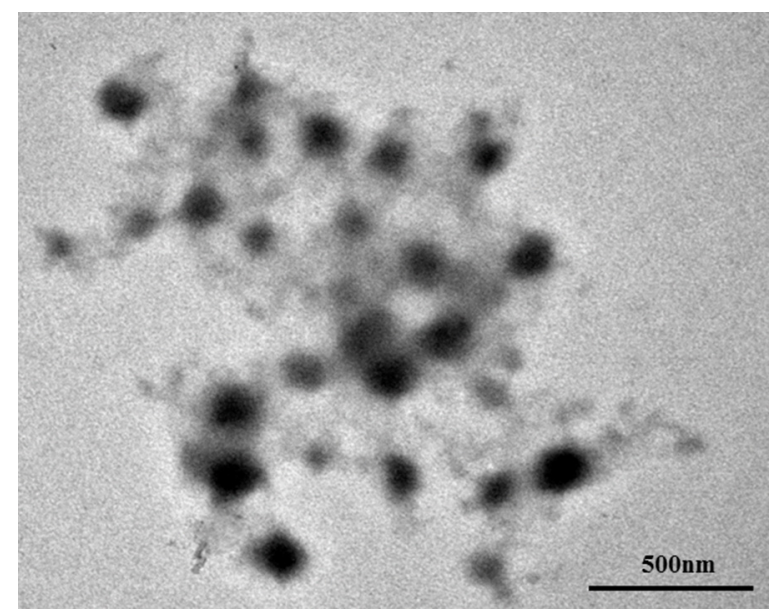

Fig. 2. TEM micrographs of $\mathrm{RNP}_{3}$. types were incubated for $24 \mathrm{~h}$ with empty RNPs at concentrations ranging from $12.510^{-3}$ to $1.6 \mathrm{mg} \mathrm{mL}^{-1}$. HaCaT cells displayed no appreciable reductions in viability at any of the RNP concentrations tested (Fig. 4A), indicating that the RNPs are likely to be safe drug

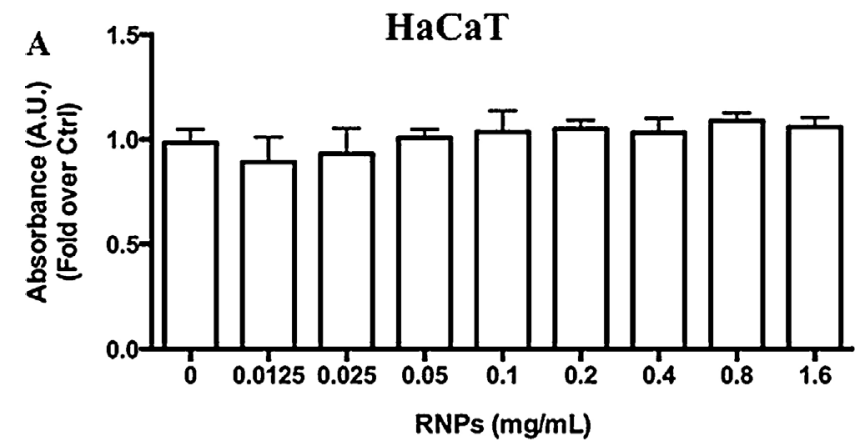

Daoy

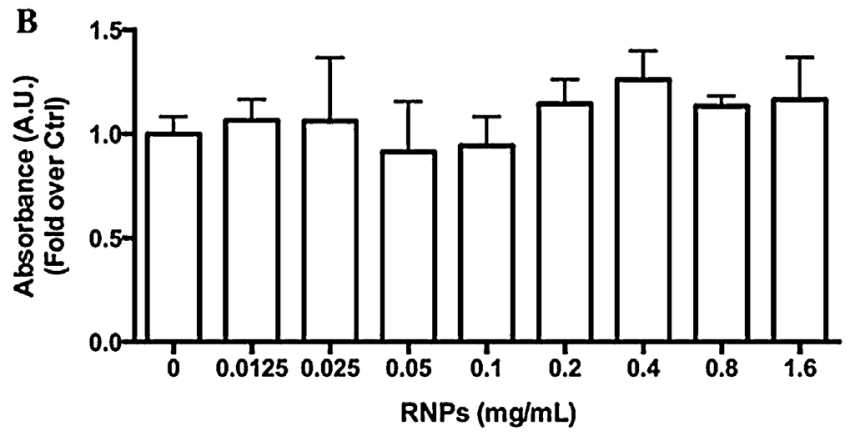

Fig. 4. Cytocompatibility of unloaded RNPs in HaCaT (A) and Daoy (B) cells. Cell viability was measured by MTS assay after $24 \mathrm{~h}$ of incubation.
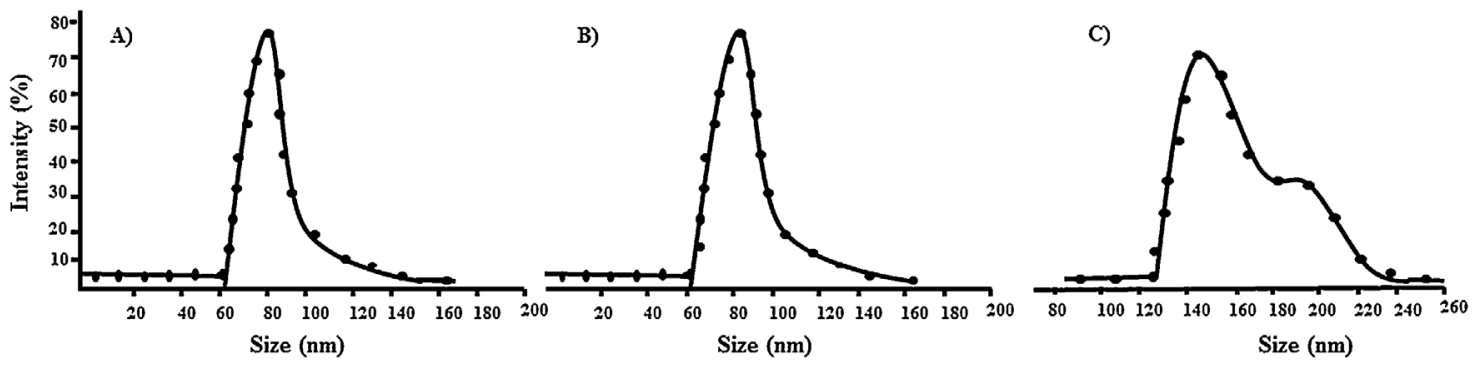

Fig. 3. DLS analysis of RNPs after $24 \mathrm{~h}$ incubation in PBS $0.1 \mathrm{M}, \mathrm{pH} 7.4$ (A); GSH $10 \mu \mathrm{M}$ in PBS 0.1, pH 7.4 (B), GSH $10 \mathrm{mM}$ in PBS $0.1, \mathrm{pH} 7.4$ (C). 
carriers for treatment of MB. Similarly, no signs of toxicity were detected in Daoy cells (Fig. 4B), confirming the complete biocompatibility of RNPs.

\subsection{Cytotoxicity studies of CPT-loaded RNPS}

Since our intention was to use the RNPs as carriers for CPT, our next step was to evaluate the cytotoxic profiles of free CPT in the two cell lines. As shown in Fig. 5A and C, both HaCaT and Daoy cells proved to be CPT-sensitive (Ho et al., 2016; Luong et al., 2016) with $\mathrm{IC}_{50}$ values of 3.71 and $2.42 \mu \mathrm{g} \mathrm{mL}^{-1}$, respectively (Table 1 ). With the aim of enhancing the drug's therapeutic index, selected amounts of RNPs were soaked in aqueous CPT solutions to produce drug:carrier ratios up to $20 \%$. (Significantly higher ratios cannot be achieved by further increases in the CPT concentration of the soaking solution.) In all cases, loading efficiencies were close to $100 \%$. Three formulations were obtained with final drug:carrier ratios of $5 \%\left(\mathrm{CPT}: \mathrm{RNP}_{1}\right), 10 \%$ (CPT:RNP ${ }_{2}$ ), and $20 \%$ (CPT:RNP $\mathrm{R}_{3}$ ).

These three CPT nanoformulations were incubated with HaCaT or Daoy cells at doses calculated to produce equivalent CPT concentrations in the range $0-16 \mu \mathrm{g} \mathrm{mL}^{-1}$. Twenty-four hours later, cell viability was assessed. As shown in Fig. 5B and D, compared with free CPT (Fig. 5A and C), CPT:RNP 2 and CPT:RNP 3 displayed lower toxicity in both cell lines, but Daoy cell viability was clearly reduced more than that of the normal keratinocyte line. In contrast, the formulation with the lowest drug:carrier ratio, CPT: $\mathrm{RNP}_{1}$, produced excessively low rates of killing in both cell lines (data not shown).

\subsection{Cellular uptake of FITC-RNPs}

Effective cellular uptake is a key requisite for any cellresponsive nano-carrier. To assess this aspect, we labeled our RNPs with FITC, incubated them with HaCaT and Daoy cells (cell nuclei and cytoskeletons were stained with Hoechst blue and phalloidin-Cy 5 orange, respectively) for $3 \mathrm{~h}$, and examined FITCRNPs uptake by confocal microscopy confirming that their internalization occurs rapidly and with high efficiency. In Fig. 6A and B the dichroic (DIC) overlay shows the DIC image merged with the confocal fluorescent image of a single xy plane.
Table 1

$\mathrm{IC}_{50}$ valued for CPT and CPT nanoformulations on HaCaT and Daoy cell lines after $24 \mathrm{~h}$ incubation.

\begin{tabular}{lllll}
\hline Sample & DL(\%) & Cell Lines & $\mathrm{IC}_{50}\left(\mu \mathrm{g} \mathrm{mL}^{-1}\right)$ & $\begin{array}{l}\text { Two-tailed } p \text {-value } \\
\text { HaCaT vs DAOY }\end{array}$ \\
\hline $\mathrm{CPT}$ & - & HaCaT & 3.71 & $\mathrm{P}<0.01$ \\
& & DAOY & 2.42 & \\
$\mathrm{RNP}_{2}$ & \multirow{2}{*}{10} & HaCaT & 15.24 & $\mathrm{P}<0.0001$ \\
& & DAOY & 8.82 & \\
$\mathrm{RNP}_{3}$ & \multirow{2}{*}{20} & HaCaT & 11.17 & $\mathrm{P}<0.0001$ \\
& & DAOY & 6.19 & \\
\hline
\end{tabular}

Orthogonal views of the $\mathrm{xy}, \mathrm{xz}$ and $\mathrm{yz}$ single planes at the indicated orthogonal xyz axes (white lines) of HaCaT and Daoy cells (Fig. 6C and D) shows the localization of FITC-loaded RNPs relative to subcellular compartments, while the three-dimensional reconstructions from 17 planes highlight the intracellular localization of FITC-loaded RNPs relative to the surfaces HaCaT and Daoy cells. (Fig. 6E and F).

\section{Discussion}

The aims of our study were to evaluate the in vitro efficacy and safety of CPT-loaded RNPs for the treatment of MBs. As shown in Fig. 1, the BSA RNPs we synthesized were cross-linked with BAC. From a chemical point of view, the reaction we planned involves the addition of a nucleophile to an activated electrophilic olefin under mild reaction conditions. This offers the advantages of high functional group tolerance and versatility (Mather et al., 2006). The decision to crosslink the RNPs with BAC, which stabilizes the RNPs by the formation of disulfide bonds, allowed us to obtain RNPs that were responsive to the redox status of the intracellular environment. Because the RNPs were designed for use in the treatment of MBs, we used TEM/DLS to confirm that they were small enough to effectively penetrate the blood-brain barrier (BBB) (Fig. 2).

A key requirement for any drug-delivery vehicle is the complete absence of negative effects on the viability of healthy cells (Curcio et al., 2015d). We therefore tested the activity of empty RNPs at concentrations ranging from $12.510^{-3}$ to $1.6 \mathrm{mg} \mathrm{mL}^{-1}$. As shown in
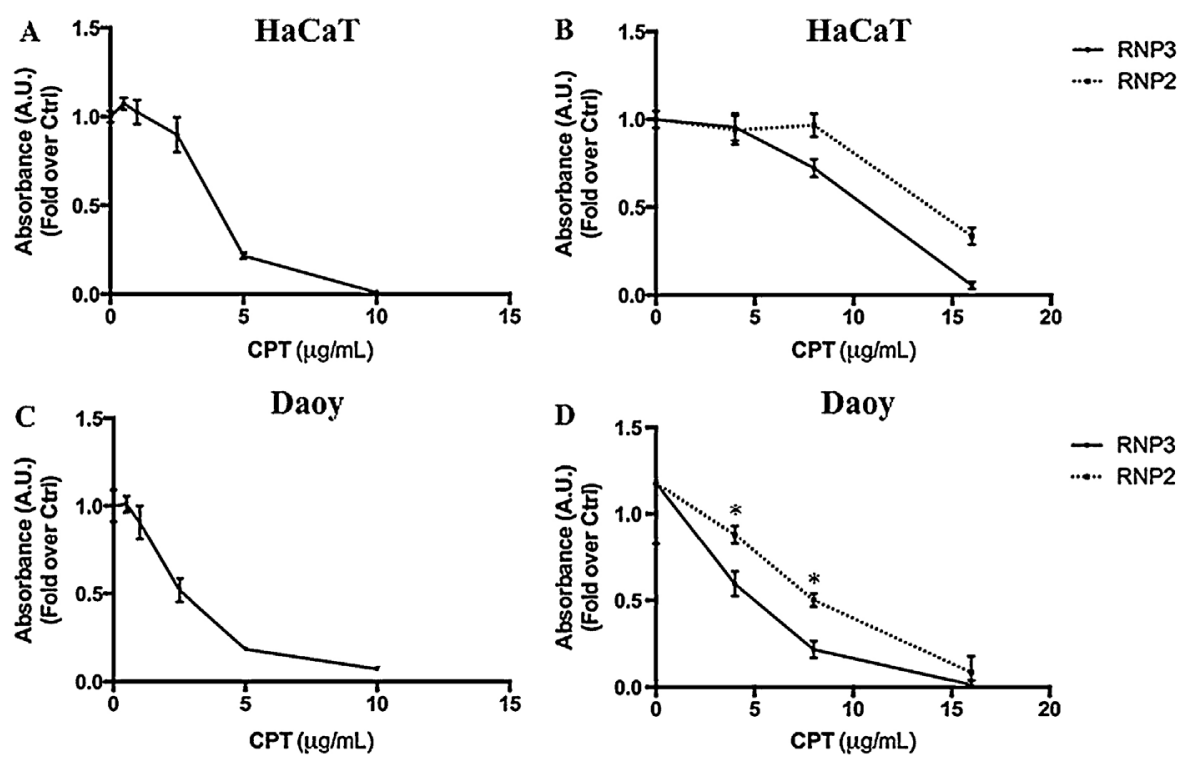

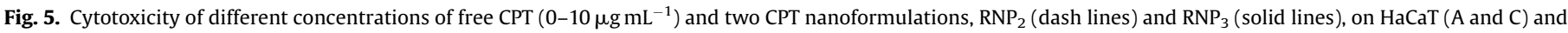
Daoy (B and D) cells. * $\mathrm{p}<0.05,{ }^{* *} \mathrm{p}<0.01 \mathrm{RNP}_{2}$ vs $\mathrm{RNP}_{3}$. 
A

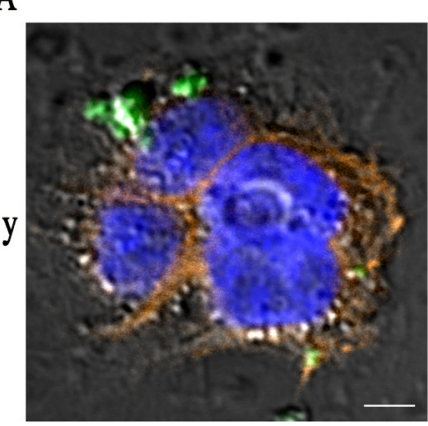

$\mathrm{C}$

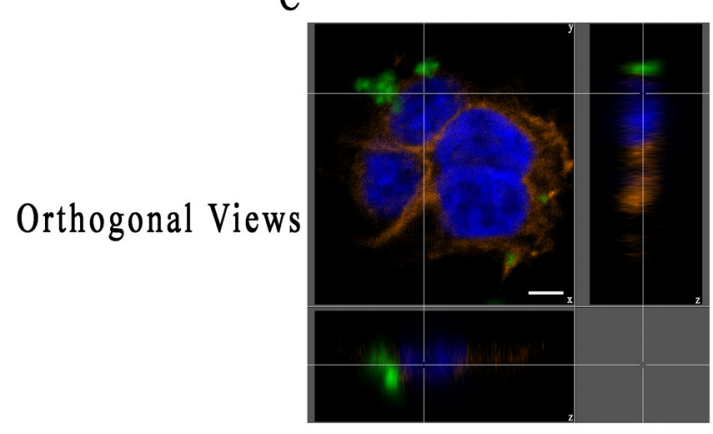

$\mathrm{E}$

3D Rendering

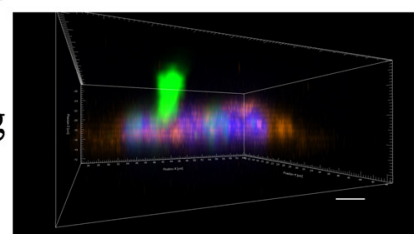

B

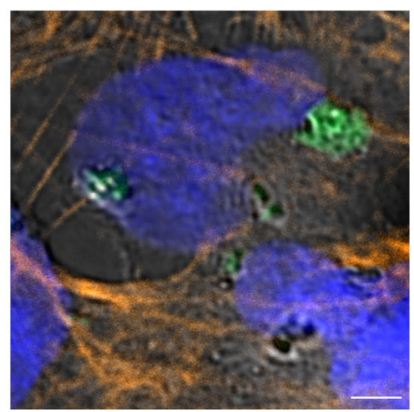

D

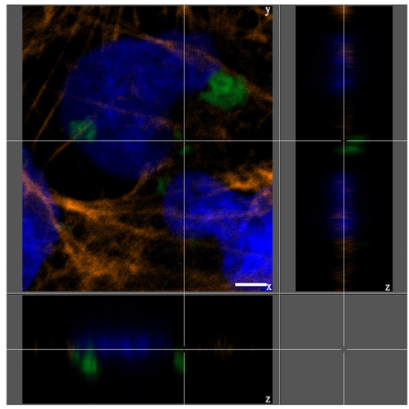

F

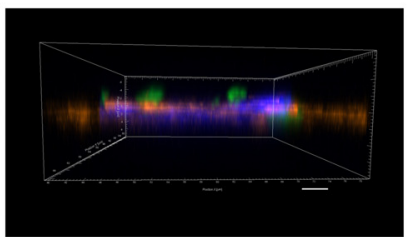

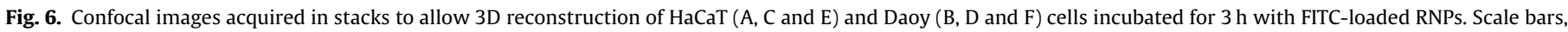
$5 \mu \mathrm{m}$.

Fig. 4, the results confirmed that the RNPs were fully biocompatible in both cell models.

CPT displays strong cytotoxic activity in many solid tumors, including testicular, ovarian, breast, bladder, lung, and head and neck cancer (Parhizkar et al., 2016). Together with radiation, it has played a pivotal role in the treatment of MB for the past two decades. However, its clinical efficacy is limited by the severe side effects it produces (Dhar et al., 2008).

Having confirmed the CPT-sensitivity of Daoy and HaCaT cells, we assessed their responses to two CPT nano-formulations with drug:carrier ratios of $10 \%\left(\mathrm{CPT}: \mathrm{RNP}_{2}\right)$ and $20 \%\left(\mathrm{CPT}: \mathrm{RNP}_{3}\right)$. The cytotoxicity of CPT loaded into RNPs is strongly influenced by the intracellular GSH levels (Wang et al., 2013b), which are higher in cancer cells than in normal cells (Curcio et al., 2015a). RNPs internalized by the Daoy cells therefore undergo enhanced disruption of their BAC crosslinking points, which leads to more marked increases in RNP size, the release of greater amounts of CPT into the intracellular environment, and more evident cytotoxicity than that produced in $\mathrm{HaCaT}$ cells, as reflected by the $\mathrm{IC}_{50}$ values in Table 1 . These data clearly show that free CPT is less effective in killing HaCaT cells, where its $\mathrm{IC}_{50}$ is 1.53 times higher than that recorded for Daoy cells. The difference is even more marked when CPT nano-formulations are used: the $\mathrm{IC}_{50}$ values for CPT: $\mathrm{RNP}_{2}$ and $\mathrm{CPT}: \mathrm{RNP}_{3}$ in the HaCaT cells are 1.73 and 1.80 times higher, respectively, than those recorded in Daoy cells. This effect can be attributed to the fact that the size of the RNPs is relatively unaffected by the lower GSH concentrations that are typical of HaCaT cytosol (see DLS analyses), and under these conditions the amount of CPT released by the NPs (and consequently, its cytotoxicity) is appreciably reduced.

It should be highlighted that, due to the higher drug:carrier ratio, RNP3 displayed more intense cytotoxicity than RNP2, as reflected by lower IC50 values. More interestingly, RNP3 showed higher selectivity for the neoplastic cells than free $\mathrm{CPT}$, as a results of their capability to modulate the release of cytotoxic drug into cancer cells, increasing its intracellular concentration.

\section{Conclusions}

In this study we proposed a novel approach for Medulloblastoma treatment based on the redox-responsive delivery of cisplatin by bovine serum albumin nanoparticles. A two steps procedure consisting of desolvation and crosslinking with $N, N^{\prime}$-Bis (acryloyl) cystamin processes was employed for the preparation of RNP with dimensional range in the nanoscale and a narrow dimensional range. The core results of the study is the possibility to modulate the efficiency of the cytotoxic drug as a function of the intracellular GSH content. At high GSH content, the crosslinker is cleaved promoting the RNP destabilization and thus the drug release. As a consequence, higher toxic effect is recorded in Daoy against HaCaT cell lines, with an enhancement of the therapeutic index.

Although the promising results of our study are undeniably preliminary, they provide encouraging support for continuing efforts to develop more cell-specific delivery systems for antineoplastic drugs, particularly those used to treatment tumors in highly vulnerable tissues like those of the CNS. 


\section{Acknowledgments}

This work was financially supported by University of Calabria funds. The authors wish to thank the IIT-CLNS@Sapienza imaging facility and Dr. Valeria De Turris for her technical support on confocal microscopy. This work was supported by Pasteur Institute/Cenci Bolognetti Foundation and Sapienza University of Rome (Ateneo). Medical writing support was provided by M.E. Kent (EMWA) and funded by the Società Italiana Articoli Laboratorio S.r.l (Rome, Italy).

\section{References}

Bergonzi, M.C., Guccione, C., Grossi, C., Piazzini, V., Torracchi, A., Luccarini, I., Casamenti, F., Bilia, A.R., 2016. Albumin nanoparticles for brain delivery: a comparison of chemical versus thermal methods and in vivo behavior. ChemMedChem 1840-1849.

Calvo, P., Gouritin, B., Chacun, H., Desmaile, D., D'Angelo, J., Noel, J.P., Georgin, D., Fattal, E., Andreux, J.P., Couvreur, P., 2001. Long-circulating pegylated polycyanoacrylate nanoparticles as new drug carrier for brain delivery. Pharm. Res. 18, 1157-1166.

Chen, L., Chen, F., Zhao, M., Zhu, X., Ke, C., Yu, J., Yan, Z., Zhang, F., Sun, Y., Chen, D., Jiang, C., Zhao, X., Gao, Y., Guo, S., Li, W., 2015. A redox-sensitive micelle-like nanoparticle self-assembled from amphiphilic adriamycin-human serum albumin conjugates for tumor targeted therapy. BioMed Res. Int. 2015.

Coluccia, D., Figuereido, C., Isik, S., Smith, C., Rutka, J.T., 2016. Medulloblastoma: tumor biology and relevance to treatment and prognosis paradigm. Curr. Neurol. Neurosci. Rep. 16, 1-11.

Curcio, M., Blanco-Fernandez, B., Diaz-Gomez, L., Concheiro, A., Alvarez-Lorenzo, C., 2015a. Hydrophobically modified keratin vesicles for GSH-responsive intracellular drug release. Bioconjugate Chem. 26, 1900-1907.

Curcio, M., Blanco-Fernández, B., Costoya, A., Concheiro, A., Puoci, F., AlvarezLorenzo, C., 2015b. Glucose cryoprotectant affects glutathione-responsive antitumor drug release from polysaccharide nanoparticles. Eur. J. Pharm. Biopharm. 93, 281-292.

Curcio, M., Cirillo, G., Vittorio, O., Spizzirri, U.G., Iemma, F., Picci, N., 2015c. Hydrolyzed gelatin-based polymersomes as delivery devices of anticancer drugs. Eur. Polym. J. 67, 304-313.

Curcio, M., Spizzirri, U.G., Cirillo, G., Vittorio, O., Picci, N., Nicoletta, F.P., Iemma, F., Hampel, S., 2015d. On demand delivery of ionic drugs from electro-responsive CNT hybrid films. RSC Adv. 5, 44902-44911.

Dhar, S., Gu, F.X., Langer, R., Farokhza, O.C., Lippard, S.J., 2008. Targeted delivery of cisplatin to prostate cancer cells by aptamer functionalized Pt(IV) prodrugPLGA - PEG nanoparticles. Proc. Natl. Acad. Sci. U. S. A. 105, 17356-17361.

Eetezadi, S., Ekdawi, S.N., Allen, C., 2015. The challenges facing block copolymer micelles for cancer therapy: in vivo barriers and clinical translation. Adv. Drug Deliv. Rev. 91, 7-22.

Elzoghby, A.O., Samy, W.M., Elgindy, N.A., 2012. Albumin-based nanoparticles as potential controlled release drug delivery systems. J. Controlled Release 157, $168-182$.

Fernandes, E., Ferreira, J.A., Andreia, P., Luís, L., Barroso, S., Sarmento, B., Santos, L.L., 2015. New trends in guided nanotherapies for digestive cancers: a systematic review. J. Controlled Release 209, 288-307.

Gharpure, K.M., Wu, S.Y., Li, C., Lopez-Berestein, G., Sood, A.K., 2015 Nanotechnology: future of oncotherapy. Clin. Cancer Res. 21, 3121-3130.

Hervé, F., Ghinea, N., Scherrmann, J.M., 2008. CNS delivery via adsorptive transcytosis. AAPS J. 10, 455-472.

Ho, W.S., Feldman, M.J., Maric, D., Amable, L., Hall, M.D., Feldman, G.M., RayChaudhury, A., Lizak, M.J., Vera, J.C., Aaron Robison, R., Zhuang, Z., Heiss, J.D., 2016. PP2A inhibition with LB100 enhances cisplatin cytotoxicity and overcomes cisplatin resistance in medulloblastoma cells. Oncotarget 7, 1244712463.

Ilangovan, G., Li, H., Zweier, J.L., Kuppusamy, P., 2002. In vivo measurement of tumor redox environment using EPR spectroscopy. Mol. Cell. Biochem. 234-235, 393398.

Johnstone, T.C., Suntharalingam, K., Lippard, S.J., 2016. The next generation of platinum drugs: targeted Pt(II) agents, nanoparticle delivery, and Pt(IV) prodrugs. Chem. Rev. 116, 3436-3486.

Jun, J.Y., Nguyen, H.H., Paik, S.Y.R., Chun, H.S., Kang, B.C., Ko, S., 2011. Preparation of size-controlled bovine serum albumin (BSA) nanoparticles by a modified desolvation method. Food Chem. 127, 1892-1898.

Kaushik, K.H., Sripuram, V.K., Bedada, S., Reddy, N.Y., Priyadarshini, G.I., Devarakonda, K.R., 2010. A simple and sensitive validated HPLC method for quantitative determination of cisplatin in human plasma. Clin. Res. Regul. Affairs 27, 1-6.
Ke, C.Y., Wu, Y.T., Tseng, W.L., 2015. Fluorescein-5-isothiocyanate-conjugated protein-directed synthesis of gold nanoclusters for fluorescent ratiometric sensing of an enzyme-substrate system. Biosens. Bioelectron. 69, 46-53.

Kim, B.Y.S., Rutka, J.T., Chan, W.C.W., 2010. Current concepts: nanomedicine. New Engl. J. Med. 363, 2434-2443.

Kumari, P., Ghosh, B., Biswas, S., 2016. Nanocarriers for cancer-targeted drug delivery. J. Drug Target. 24, 179-191.

Laner-Plamberger, S., Wolff, F., Kaser-Eichberger, A., Swierczynski, S., HauserKronberger, C., Frischauf, A.M., Eichberger, T., 2013. Hedgehog/GLI signaling activates suppressor of cytokine signaling 1 (SOCS1) in epidermal and neural tumor cells. PLoS One 8.

Luong, K.V., Wang, L., Roberts, B.J., Wahl, J.K., Peng, A., 2016. Cell fate determination in cisplatin resistance and chemosensitization. Oncotarget 7, 23383-23394.

Mather, B.D., Viswanathan, K., Miller, K.M., Long, T.E., 2006. Michael addition reactions in macromolecular design for emerging technologies. Prog. Polym. Sci. (Oxford) 31, 487-531.

Matheson, C.J., Venkataraman, S., Amani, V., Harris, P.S., Backos, D.S., Donson, A.M. Wempe, M.F., Foreman, N.K., Vibhakar, R., Reigan, P., 2016. A WEE1 inhibitor analog of AZD1775 maintains synergy with cisplatin and demonstrates reduced single-agent cytotoxicity in medulloblastoma cells. ACS Chem. Biol.11, 921-930.

Molina, A.M., Morales-Cruz, M., Benítez, M., Berríos, K., Figueroa, C.M., Griebenow, K., 2016. Redox-sensitive cross-linking enhances albumin nanoparticle function as delivery system for photodynamic cancer therapy. J. Nanomed. Nanotechnol. 6, 1000294.

Morfouace, M., Shelat, A., Jacus, M., Freeman, B.B., Turner, D., Robinson, S., Zindy, F., Wang, Y.D., Finkelstein, D., Ayrault, O., Bihannic, L., Puget, S., Li, X.N., Olson, J., Robinson, G.W., Guy, R., Stewart, C.F., Gajjar, A., Roussel, M.F., 2014. Pemetrexed and gemcitabine as combination therapy for the treatment of group3 medulloblastoma. Cancer Cell 25, 516-529.

Nageswara Rao, A.A., Wallace, D.J., Billups, C., Boyett, J.M., Gajjar, A., Packer, R.J., 2014. Cumulative cisplatin dose is not associated with event-free or overall survival in children with newly diagnosed average-risk medulloblastoma treated with cisplatin based adjuvant chemotherapy: report from the children's oncology group. Pediatr. Blood Cancer 61, 102-106.

Neumann, E., Frei, E., Funk, D., Becker, M.D., Schrenk, H.H., Mller-Ladner, U., Fiehn, C. 2010. Native albumin for targeted drug delivery. Expert Opin. Drug Deliv. 7, 915925.

Noguchi, Y., Wu, J., Duncan, R., Strohalm, J., Ulbrich, K., Akaike, T., Maeda, H., 1998 Early phase tumor accumulation of Macromolecules: a great difference in clearance rate between tumor and normal tissues. Jpn. J. Cancer Res. 89, 307314.

Pacardo, D.B., Ligler, F.S., Gu, Z., 2015. Programmable nanomedicine: synergistic and sequential drug delivery systems. Nanoscale 7, 3381-3391.

Parhizkar, M., Reardon, P.J.T., Knowles, J.C., Browning, R.J., Stride, E., Barbara, P.R., Harker, A.H., Edirisinghe, M., 2016. Electrohydrodynamic encapsulation of cisplatin in poly (lactic-co-glycolic acid) nanoparticles for controlled drug delivery. Nanomed.: Nanotechnol. Biol. Med. 12, 1919-1929.

Qiu, Y., Park, K., 2012. Environment-sensitive hydrogels for drug delivery. Adv. Drug Deliv. Rev. 64, 49-60.

Raval, N., Mistry, T., Acharya, N., Acharya, S., 2015. Development of glutathioneconjugated asiatic acid-loaded bovine serum albumin nanoparticles for braintargeted drug delivery. J. Pharm. Pharmacol. 67, 1503-1511.

Shi, H., Cheng, Q., Yuan, S., Ding, X., Liu, Y., 2015. Human serum albumin conjugated nanoparticles for $\mathrm{pH}$ and redox-responsive delivery of a prodrug of cisplatin. Chem. - Eur. J. 21, 16547-16554.

Stylianopoulos, T., Jain, R.K., 2015. Design considerations for nanotherapeutics in oncology. Nanomed.: Nanotechnol. Biol. Med. 11, 1893-1907.

Sun, Y., Yan, X., Yuan, T., Liang, J., Fan, Y., Gu, Z., Zhang, X., 2010. Disassemblable micelles based on reduction-degradable amphiphilic graft copolymers for intracellular delivery of doxorubicin. Biomaterials 31, 7124-7131.

Ulbrich, K., Hekmatara, T., Herbert, E., Kreuter, J., 2009. Transferrin- and transferrinreceptor-antibody-modified nanoparticles enable drug delivery across the blood-brain barrier (BBB). Eur. J. Pharm. Biopharm. 71, 251-256.

Wang, A.Z., Langer, R., Farokhzad, O.C., 2012. Nanoparticle delivery of cancer drugs. Annu. Rev. Med. 185-198.

Wang, W., Huang, Y., Zhao, S., Shao, T., Cheng, Y., 2013a. Human serum albumin (HSA) nanoparticles stabilized with intermolecular disulfide bonds. Chem. Commun. 49, 2234-2236.

Wang, X., Cai, X., Hu, J., Shao, N., Wang, F., Zhang, Q., Xiao, J., Cheng, Y., 2013b. Glutathione-triggered off-On release of anticancer drugs from dendrimerencapsulated gold nanoparticles. J. Am. Chem. Soc. 135, 9805-9810.

Wehe, C.A., Beyer, G., Sperling, M., Ciarimboli, G., Karst, U., 2014. Assessing the intracellular concentration of platinum in medulloblastoma cell lines after Cisplatin incubation. J. Trace Elem. Med. Biol. 28, 166-172.

Wolak, D.J., Thorne, R.G., 2013. Diffusion of macromolecules in the brain: implications for drug delivery. Mol. Pharm. 10, 1492-1504.

Wolff, F., Loipetzberger, A., Gruber, W., Esterbauer, H., Aberger, F., Frischauf, A.M., 2013. Imiquimod directly inhibits Hedgehog signalling by stimulating adenosine receptor/protein kinase A-mediated GLI phosphorylation. Oncogene 32, 5574-5581. 